\title{
Climate change-induced impacts on urban flood risk influenced by concurrent hazards
}

\author{
Nedergaard Pedersen, Agnethe; Mikkelsen, Peter Steen; Arnbjerg-Nielsen, Karsten
}

Published in:

Journal of Flood Risk Management

Link to article, DOI:

10.1111/j.1753-318X.2012.01139.x

Publication date:

2012

Document Version

Publisher's PDF, also known as Version of record

Link back to DTU Orbit

Citation (APA):

Nedergaard Pedersen, A., Mikkelsen, P. S., \& Arnbjerg-Nielsen, K. (2012). Climate change-induced impacts on urban flood risk influenced by concurrent hazards. Journal of Flood Risk Management, 5(3), 203-214.

https://doi.org/10.1111/j.1753-318X.2012.01139.x

\section{General rights}

Copyright and moral rights for the publications made accessible in the public portal are retained by the authors and/or other copyright owners and it is a condition of accessing publications that users recognise and abide by the legal requirements associated with these rights.

- Users may download and print one copy of any publication from the public portal for the purpose of private study or research.

- You may not further distribute the material or use it for any profit-making activity or commercial gain

- You may freely distribute the URL identifying the publication in the public portal

If you believe that this document breaches copyright please contact us providing details, and we will remove access to the work immediately and investigate your claim. 


\title{
Climate change-induced impacts on urban flood risk influenced by concurrent hazards
}

\author{
A.N. Pedersen*, P.S. Mikkelsen and K. Arnbjerg-Nielsen \\ Department of Environmental Engineering (DTU Environment), Technical University of Denmark, Lyngby, Denmark
}

\author{
Correspondence \\ K. Arnbjerg-Nielsen, Department of \\ Environmental Engineering (DTU \\ Environment), Technical University of \\ Denmark, Miljoevej, Bldg 113, DK-2800 \\ Kgs. Lyngby, Denmark \\ Email: karn@env.dtu.dk \\ DOI: 10.1111/j.1753-318X.2012.01139.x \\ *Present address: Rambøll Danmark, \\ Englandsgade 25, DK-5000 Odense C, \\ Denmark (Email: agnl@ramboll.dk)
}

Key words

Climate change; risk assessment;

simulation modelling; urban.

\begin{abstract}
In coastal regions, several hazards may lead to floods, and if they occur concurrently, the damage will be higher than for the hazards individually. The paper outlines an approach for carrying out a risk analysis with several hazards and applies it on a case study in Greater Copenhagen where two hazards, rainfall and sea surge, are both important. The core in the methodology is the application of copula functions as an extension of one-dimensional risk analysis and projections of future climatic changes. The results for Greater Copenhagen indicate that the dependence between the hazards is weak and that climate change most likely will not increase the correlation. The overall change in flood return periods over a forecast horizon of 110 years are estimated to decrease by one to three orders of magnitude.
\end{abstract}

\section{Introduction}

Extreme weather events giving rise to flooding in urban areas are expected to occur more frequently in the future because of anthropogenic climate change, and several studies indicate that these changes can already be observed in historical records (EU, 2007; Solomon et al., 2007; Madsen et al., 2009). The natural hazards causing flooding include heavy rain storms that lead to pluvial flooding before the runoff enters any watercourse or sewer, fluvial flooding from rivers and other watercourses, coastal flooding from seas and estuaries driven by, e.g. tidal waves and storm surges, and rising groundwater levels caused by combinations of the aforementioned. Several additional phenomena commonly contribute to urban flooding, such as limited conveyance capacity of urban channels and rivers as well as drains and sewers because of blockages and infiltration-inflow, and decades of urban development without upgrading of the drainage infrastructure. The topography of the urban landscape furthermore affects how the surcharging water flows on the urban surfaces during heavy rainstorms and the damage incurred. While these mechanisms can, to some extent, be analysed using state-of-the-art integrated urban hydraulic modelling systems that currently undergo significant developments (Chen et al., 2010; Sto. Domingo et al., 2010), each hazard is usually analysed separately as individual model forcings, i.e. inputs or boundary conditions (e.g. Morita, 2008). This is partly because the probability of concurrent events historically has been small and partly because methods for a systematic analysis of concurrent hydrologic phenomena have been missing in the hydrological toolbox. Climate change may, however, increase the frequency and the magnitude and change the seasonality of extreme events, which means that concurrent flood hazards of importance to urban flood risk management may occur more frequently in the future.

Flood risk assessment is often defined as the combination of the probability of a flood occurrence and the potential adverse consequences of the event. The outcome of a flood risk assessment is therefore an overview of what will happen when extreme events occur, and it can be measured in monetary, societal, or other costs. Higher flood levels will in general lead to higher adverse effects, but they will also occur less frequently. Thus, the maximum flood risk on a longterm basis may be caused by events with moderate return periods. Flood risk assessment frameworks such as the European Flood Risk Directive (EFRD; EU, 2007) are usually applied considering a single type of flooding, typically either storm surges or fluvial floods (Myronidis et al., 2009). However, it would clearly be advantageous to make a joint analysis including all relevant flood hazards in one flood risk assessment.

The objective of this study is hence to develop and illustrate the usefulness of a methodology for analysis of simul- 
taneously occurring hazards in relation to climate change impacts on urban flooding. Fundamental parts of this methodology are to link state-of-the-art methods within regional climate modelling, urban flood modelling and statistical copulas in combination with Monte Carlo (MC) simulation in a way that is coherent with the risk assessment framework of the EFRD (EU, 2007). Regional climate models (RCMs)_are currently used worldwide to predict the potential future development of climatic hazards (frequency, magnitude, and seasonality) and as a basis for predicting changing risks and for evaluating adaptation measures (Arnbjerg-Nielsen and Fleischer, 2009; Jeppesen et al., 2009). Urban flood modelling has made a leap forwards in recent years by combining one-dimensional sewer models with high-resolution digital elevation models and twodimensional surface water models (Schmitt et al., 2004; Smith, 2006; Chen et al., 2010; Sto. Domingo et al., 2010). Copulas are functions that link individual marginal variables into a multivariate distribution while describing their interdependency, i.e. they provide a means to mathematically calculate the probability of simultaneously occurring flood hazards for historical observations. Multivariate statistical methods for extremes are important in many disciplines such as hydrology and finance. An example of a non-copula formulation for hydrology can be found in Yue (1999). Lately, copula functions have, however, become popular because of the high flexibility in describing dependencies between variables, as can be seen in an overview of recent copula applications created by the International Association of Hydrological Sciences (STAHY, 2011). Finally, MC simulations are used to predict present and future extremes by assuming an underlying dependence structure.

The methodology is demonstrated using a specific catchment area in Copenhagen, Denmark. Being a coastal city connected to the Baltic Sea and traversed by several minor rivers that cut through the moraine sub-surface, Copenhagen is potentially influenced by several of the abovementioned flood hazards. An initial screening, however, showed extreme rainfall and storm surge to be the most important, and the methodology is therefore illustrated for the bivariate case. Finally, it is shown how the probability of flooding caused by the two hazards can be combined with the adverse effects in a simple graphical method, thus providing the basis for a complete dual-hazard flood risk assessment.

The methodology section is devoted to conceptualisation and mathematical detailing of the flood risk assessment framework based on joint probabilities. The third section then outlines the case area used as an example and shows results obtained from each of the steps included in the methodology, whereas the fourth section discusses the results and the methodology, and the main conclusions are summarised in the last section.

\section{Methodology}

\section{Flood risk assessment framework}

In general, the risk assessment output, $R$, based on only one hazard, can be formulated as

$$
R=\iint_{T, A} f(T, d(A)) d T d A=\iint_{T, A} g_{1}(T, A) \times g_{2}(d(A)) d T d A
$$

where $T$ is the return period of the hazard, $d$ is the adverse consequence of the hazard that depends on the characteristics of the study area $A, g_{1}(\cdot)$ is the actual hazard (e.g. inundation) for given $A$ and $T$, and $g_{2}(\cdot)$ is a cost function expressing the damage induced by exposure to the hazard as determined by the vulnerability of the urban environment. Note that Eqn (1) implies that the risk, $R$, becomes the expected (monetary) annual costs, and hence directly may be included in the decision process for identifying and selecting risk mitigation. Figure 1 (top) illustrates how the dominating contribution to the overall flood risk typically comes from medium return period floods, as the small and frequent floods typically cause little damage and the very large and catastrophic floods occur rarely.

When analysing several hazards, $g_{1}(T)$ is a stochastic vector where the elements are dependent. The overall risk can then be calculated by a similar integration as shown in Eqn (1) of $g_{1}(\cdot)$ and $g_{2}(\cdot)$, given that the dependence between the hazards is known. However, just as the graphical illustration in the one-dimensional case, it can be important to illustrate the contribution (and thus importance) of each of the hazards relative to each other and the vulnerability. The objective is thus to construct a $n$-dimensional relationship that quantifies the same information from $n$ hazards as the one-dimensional graph in Figure 1 (top) shows with respect to Eqn (1). An example for $n=2$ is shown in Figure 1 (bottom). The overall multiple-hazard flood risk assessment framework developed in this paper includes the steps below:

1. Identify the case area and the basic data sets for characterising the relevant hydrologic hazards and select relevant flood risk indicators expressing the vulnerability of the catchment.

2. Identify a suitable way to model the seasonal distribution of the statistical properties of the identified hazards. In this study, we focus on extreme rainfall and storm surge data and to model these by means of the partial duration series (PDS) approach, which involves analysing only the extreme region of the available data.

3. Estimate the relative change in the seasonal statistical properties of the hazards between a control (present) and a scenario (future) period and how this affects the seasonal PDS parameters of the hazards.

4. Generate synthetic time series of the hazards by MC simulations based on the seasonal PDS models for the 


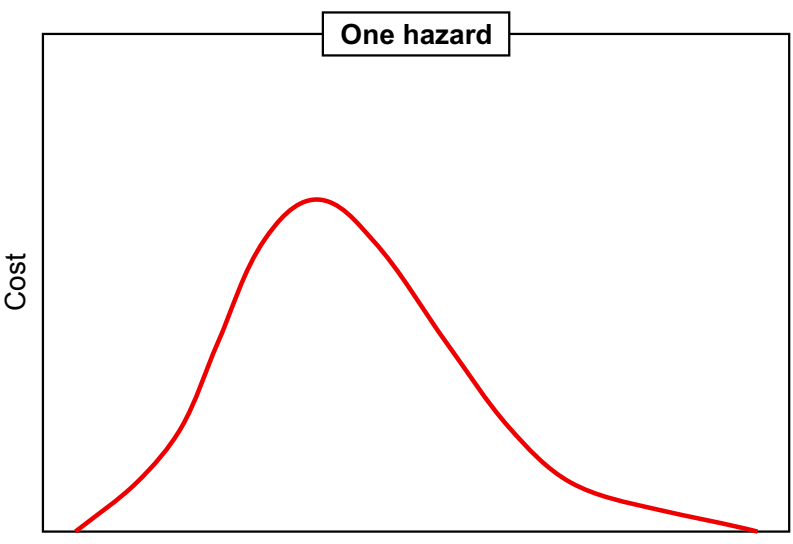

Return period, hazard

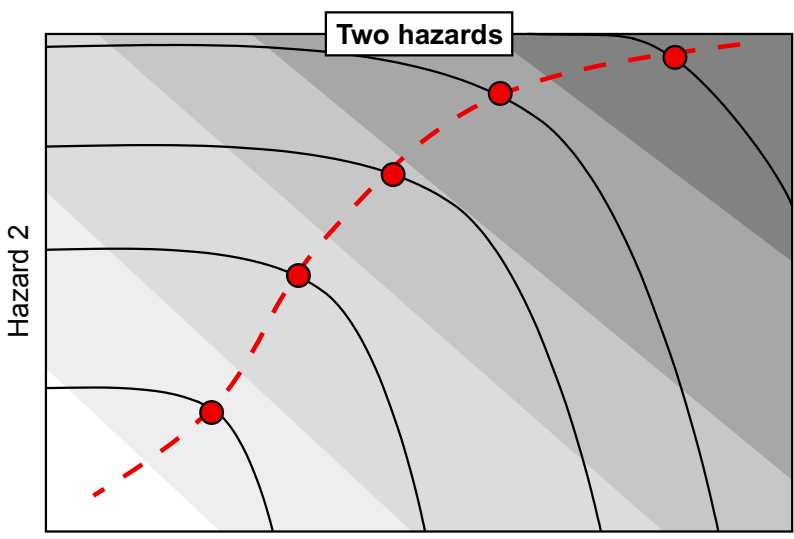

Hazard 1

Figure 1 Comparison of one- and two-dimensional risk analysis visualisations. The top figure shows which return periods contribute mostly to the overall risk in a risk framework focusing on a single hazard as shown in, e.g. Morita (2008) and Zhou et al. (2012). The bottom figure shows the return periods calculated by means of copula functions for two concurrent hazards (solid lines), a vulnerability indicator (shaded areas) and the resulting most detrimental combination of return period and vulnerability (dashed line with red markings).

control and the scenario period, to establish a data set large enough to quantify the dependence between the hazards.

5. Identify a suitable copula function to describe the dependency between the hazards and calculate the conditional probability (or return period) of concurrent events for the control and the scenario period.

6. Calculate the impact of the concurrent hazards on the cost function, $g_{2}(\cdot)$, for all relevant return periods using a suitable simulation model coupled with a digital elevation model and taking the predefined hazards as model forcings.

7. Link the conditional probability (or return period) of concurrent hazards with the cost function and illustrate this in a manner that readily reveals the overall risk level for different combinations of hazards, cf. Figure 1 (right). In Figure 1, the red dots indicate for any given return period the combination of hazards that result in the highest value of the cost function.

It is for the sake of simplicity assumed in the following that the case area does not undergo any changes in the future scenario, but such changes could be incorporated in the methodology as described by Zhou et al. (2012). Steps 2-7 of the methodology are elaborated further in the paragraphs below.

\section{PDS approach}

The PDS approach is applied to monthly data series in this study using either the generalized Pareto distribution (GPD) or exponential distribution (ED) to model the extreme events that exceed a pre-defined threshold $(\beta)$ and assuming that the number, $N$, of extreme values in a period of $T$ years follows a time-homogeneous Poisson process with intensity $\lambda$ (expected number of threshold exceedances per year). With type II sampling to define the extreme value region (fixed $N$ or $\lambda$, see, e.g. Mikkelsen et al., 1996), the distribution parameters are the threshold (sometimes referred to as the location parameter, $\beta$ ), the scale parameter $(\alpha)$ as well as a shape $(\kappa)$ parameter (for the GPD).

The cumulative density function for the GPD and ED is shown in Eqns (2) and (3), respectively (Madsen, 2005).

$$
\begin{aligned}
& F_{G P}(x)=1-\left(1+\kappa \frac{x-\beta}{\alpha}\right)^{1 / \kappa} \\
& F_{\text {exp }}(x)=1-\exp \left(-\frac{x-\beta}{\alpha}\right)
\end{aligned}
$$

where $x$ is the magnitude of the event.

The $p$-quantile of the distribution can be found by the following equation (Madsen, 2005):

$$
x_{p}=F^{-1}(p)
$$

where $p=\mathrm{P}(X \leq x)$. The $T$-year event refers to the level of $X$ that is exceeded on average once in $T$ years and is usually defined as the $[1-1 /(\lambda T)]$-quantile in the distribution of the exceedances (e.g. Rosbjerg, 1985), where $T$ denotes the return period, i.e.

$$
T=\frac{1}{(1-p) \lambda}
$$

The magnitude of a $T$-year event can then be found for the GPD and ED using Eqns (6) and (7), respectively (Madsen, 2005).

$$
\hat{x}_{T}=\beta+\frac{\alpha}{\kappa}\left[1-\left(\frac{1}{T \lambda}\right)^{\kappa}\right]
$$


$\hat{x}_{T}=\beta-\alpha \cdot \ln \left(\frac{1}{T \lambda}\right)$

The parameters $\beta, \alpha$, and $\kappa$ are here estimated from monthly series of daily data using the statistical toolbox EVA (DHI, Hoersholm, Denmark) (Madsen, 2005).

\section{Prediction of future change of flood hazards}

Once the statistical properties (PDS parameters $\lambda, \alpha$, and $\kappa$, cf. above) of the hazards have been estimated, the challenge is to predict their future values as potentially influenced by climate change. The approach taken here is to rely on simulations with RCMs downscaled from simulations with global climate models, for a control period (resembling the characteristics of the present) and for a future scenario period (resembling the characteristics of a projected future).

In the simplest case, such simulations can be used to estimate 'climate factors' (CFs)

$C F_{T}=\frac{\hat{x}_{T, \text { scenario }}}{\hat{x}_{T, \text { control }}}$

expressing the potential development in relevant flood hazards for defined return periods, $T$, because of climate change. CFs can be applied to the estimated PDS parameters based on heuristic arguments much like the delta change values used when perturbing baseline meteorological data with, e.g. monthly change values (e.g. van Roosmalen et al., 2009). This method has been applied on several studies concerning extreme precipitation hazards based on scaling of properties of extreme rainfall (e.g. Grum et al., 2006; Larsen et al., 2009; Onof and Arnbjerg-Nielsen, 2009).

The climate change impacts on other hazards related to floods are less easily calculated because the key hazard is not computed directly in the RCMs. Hence, some form of postprocessing must be carried out independently of the RCM outputs. In the case of sea surges, the regional mean changes of the sea level relative to the land must be added to the maximum current surge statistics as well as a measure of changes in wind-induced changes in wave height extremes. In this study, we find a good correlation between monthly extremes of wind speed from RCMs as calculated by Rockel and Woth (2007) and observed monthly extremes of water levels in the control period. Based on this empirical finding, we establish a method for constructing future sea surges. When evaluating future occurrences of fluvial floods and groundwater-induced floods, actual hydrological models must be set up, e.g. van Roosmalen et al. (2009).

\section{MC generation of times series of flood hazards extremes}

The historical recordings of the time series of flood hazards are in general too short to allow direct estimation of the copula functions and, furthermore, time series are obviously not available for a potential future influenced by climate change. Therefore, artificial series of extremes of the hydrological hazards are generated based on MC simulations using PDS models described above. Two synthetic periods are simulated representing the control period (present climate scenario, 1961-1990) and the future scenario period (20712100 ), respectively. A daily time step is used, which can be justified by the catchment and phenomena under study (as explained in the Application example). Generation of the artificial time series of extremes are carried out in the following manner:

1. Randomly generate, for each flood hazard and for both the control and the future scenario, from a uniform distribution a set of data between 0 and 1 for each day, $d$, of each month, $m$, in a 1000 -year period

$$
\begin{aligned}
r_{i}, i & =(1, \ldots,(d=1, \ldots, 30 ; m=1, \ldots, 12 ; y=1, \ldots, 1000)), \\
r_{i} & \in[0 ; 1]
\end{aligned}
$$

If $r_{i}$ is larger than (1- $\lambda$ ) (i.e. the monthly rate of occurrence of extremes in the Poisson process), then the date is considered to contain an extreme event for the particular hazard.

2. The magnitude of each extreme event is calculated by Eqn (6) or Eqn (7), respectively, where $T$ is calculated by Eqn (5) using $r_{i}$ as $p$.

The generated daily time series will then consist of a date and a vector of randomly generated values of extremes, one for each flood hazard.

The artificial time series are generated assuming no correlation between the occurrences of extreme hazards, except for covariation due to seasonal variation of the probability of extremes. If the resulting artificial time series has a different correlation structure between the extremes than that observed in the historical observations, the simulations can be improved by making conditional simulation of an extreme given that another extreme has occurred.

\section{Copula}

The theoretical basis for copulas was mentioned by Sklar (1959, cited in Nelsen, 2006) but has recently been introduced in topics such as hydrology (Serinaldi and Grimaldi, 2007; Singh and Zhang, 2007; Zhang and Singh, 2007; Schölzel and Friederichs, 2008; Chowdhary et al., 2009; Pinya et al., 2009; STAHY, 2011). The joint distribution between two random variables $X$ and $Y$ is given by (Zhang and Singh, 2007)

$H(x, y)=P(X \leq x, Y \leq y)=\int_{-\infty}^{x} \int_{-\infty}^{y} h(u, v) d u d v$

where $x$ is a value of $X$, and $y$ is a value of $Y$. To express the copula function of two random variables, the Archimedean family of copulas can be used. Here, $U=F X(x)$ and $V=F Y(y)$ are uniformly distributed random variables, and $u$ 
and $v$ are specific values of $U$ and $V$, respectively (Zhang and Singh, 2007). The one parameter Archimedean copula is given by

$C_{\theta}(u, v)=\phi^{-1}(\phi(u)+\phi(v))=H(x, y)$

where $\phi$ is a copula generator and should be a convex decreasing function where $\phi(1)=0$ and $\phi^{-1}(0)=0$, when $u$ or $v \geq \phi(0)$ (Zhang and Singh, 2007). Several copula families are available, but we chose the Gumbel-Hougaard copula because closed-form relations are available:

$C_{\theta}=\exp \left(\left[-(-\ln u)^{\theta}+(-\ln v)^{\theta}\right]^{1 / \theta}\right), \quad \phi_{\theta}(t)=(-\ln t)^{\theta}$

where the copula-parameter $\theta$ represents the degree of association between the two variables and is estimated from Kendall's tau coefficient of correlation $(\tau)$ between $u$ and $v$ (Zhang and Singh, 2007; Pinya et al., 2009):

$\theta=\frac{1}{1-\tau}$

Kendall's tau can be calculated as (Pinya et al., 2009):

$\tau(X, Y)=\frac{4 P}{N(n-1)}-1 ; \quad P=\sum_{i=1}^{N} n_{i}$

where $N$ is the number of observations, and $n_{i}$ is the number of $Y^{\prime} \mathrm{s}\left(Y_{i+1}, \ldots, Y_{N}\right)$ in a ranked order of $X$ that are higher than $Y_{i}$. Goodness-of-fit procedures are discussed in, e.g. Genest et al. (2007), who presents a review of methods.

For a bivariate distribution using PDS, the following is valid for the joint return period (Zhang and Singh, 2007).

$T_{X, Y}(x, y)=\frac{1}{\lambda \cdot(1-H(x, y))}$

Eqn (15) indicates that either $x$ or $y$ or both $x$ and $y$ are exceeded once every $T$ years. To find the return period of the concurrent event, where both $x$ and $y$ are exceeded, Eqn (16) can be used (Viessman and Lewis, 2003).

$P(X \cup Y)=P(X)+P(Y)-P(X \cap Y)$

where $P(X \cup Y)$ is the probability for two events to be union, thereby the term 'the probability of $X$ or $Y$ ' and $P(X \cap Y)$ is the probability for two events to be concurrent, thereby the term 'the probability of $X$ and $Y^{\prime} . P(X)$ and $P(Y)$ are found from the extreme value distribution of the single event.

It should be mentioned that copulas in this article is used for combining two random variables. Extensions to threedimensional applications of the copula method are relatively easily accomplished as shown by, e.g. Serinaldi and Grimaldi (2007) and Pinya et al. (2009).

\section{Calculation of vulnerability}

The vulnerability of the catchment is quantified in terms of the cost function, $g_{2}(\cdot)$. Calculation of the cost function is not the key aspect of the study, and hence the amount of flooded area is used to represent $g_{2}(\cdot)$. A model is set up for the urban drainage system including the surface topography to calculate the flood hazards in the area given the external forcings rainfall extremes and/or sea surges. The simulation program used is Mike Flood (Sto. Domingo et al., 2010; DHI, 2011), consisting of a Mike Urban module to simulate one-dimensional flows in the urban drainage system, and a Mike 21 module to simulate two-dimensional flows on the surface. Inputs are the complete sewer network including outlets to the low-lying river and the coastal area, and a digital terrain model with a resolution of 1 point per square metre. The storm surge is modelled by fixing the water level in the coastal cells of the digital terrain model to that of the storm surge level. Thereby the hydraulic head needed to force the water out of the catchment area is represented realistically.

\section{Linking concurrent probabilities with flood hazard indicators}

In a risk framework considering only one hazard, it is easy to map the combination of the return period of the hazard and the corresponding cost as shown in Figure 1 (top) (e.g. Morita, 2008). Such a figure illustrates the contribution of each return period to the overall risk, $R$. Correspondingly, it is of interest to see which hazard contributes the most to the overall risk by combining information about several hazards and the vulnerability. This can be done as suggested in Figure 1 (bottom) for the case of two hazards. The artificial example shows a case where the two hazards are equally important for low-return periods. For medium-return periods, the dashed line is almost vertical, indicating that hazard 2 is the most important for these return periods. By depicting $R(T)$ corresponding to the course of the dashed line, a curve similar to the one-dimensional case can be achieved.

\section{Application example}

\section{Catchment and historical observations}

The case area studied is the downstream part of a $70-\mathrm{km}^{2}$ catchment in Greater Copenhagen, Denmark. Copenhagen is a coastal city connected to the Baltic Sea via the Øresund belt. The considered area covers part of the Købanhavn and Hvidovre municipalities, which are separated by the Harrestrup $\AA$ river that discharges into the Kalveboderne bay. The part of the catchment that is most vulnerable to flooding is shown in Figure 2 (left). Harrestrup $\AA$ river has very low dry weather flows, but it receives substantial amounts of wet weather discharges from separate and combined sewer systems. Due to a very high rate of urbanisation, the concen- 

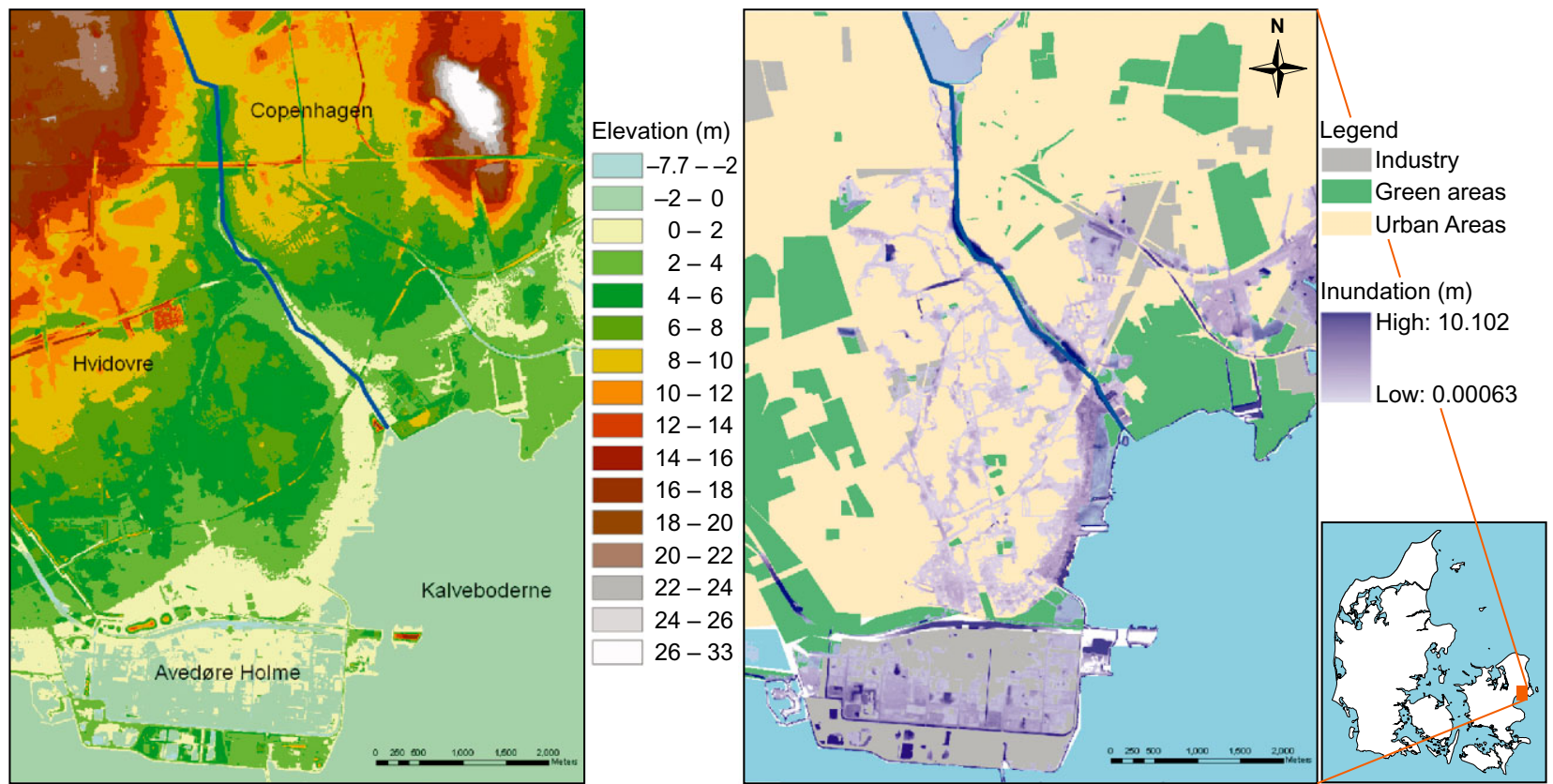

Figure 2 Case study area. Left: digital terrain model of the downstream catchment area. Right: flooding in the area when a rainfall event of $100 \mathrm{~mm} / 3 \mathrm{~h}$ happens at the same time as a water level in the bay of $2 \mathrm{~m}$. A dike protects Avedøre Holme from direct flooding from the surge, which is why flooding is relatively modest in this low-lying area. The simulated inundation shown in the figure corresponds to an extreme event with a calculated return period of more than 1000000 years in the present climate.

tration time is about $3 \mathrm{~h}$. Kalveboderne is connected to Øresund, and both the river and the catchment are thus vulnerable to storm surges from the Baltic. For the sake of simplicity, we chose the spatial extent of flooding as a simple way to represent the vulnerability. Some of the coastal areas are protected with dikes, especially near industrial areas.

Sonnenborg et al. (2006) studied the potential impacts of climate change on water resources in Denmark and concluded that the seasonal distribution of streamflow and groundwater levels are not subject to change, and neither are currently considered critical to flooding in the area, due to manmade drains and manipulated riverbeds ensuring very high flow capacity of the river. Excluding these effects allows focusing this study on the effects from extreme rainfall (pluvial flooding) and storm surges (coastal flooding). Figure 2 (right) shows an example of a simulated flooding caused by a combination of extreme rainfall and a high water level in the bay illustrating that as expected, the flooded areas appear along the coast (mainly due to the surge) as well as inside the urban catchment (due to the extreme precipitation load).

Observed rainfall data (1979-2008, i.e. 30 years) from a tipping bucket gauge with $0.2 \mathrm{~mm}$ resolution at Hvidovre waterworks was used to derive statistical 3-h duration rainfall events (matching the hydrological response time of the catchment) that could be used as representative rainfall input. This gauge is part of the Danish regional network of high-resolution rain gauges (Jørgensen et al., 1998; DMI, 2009), for which regional intensity-duration-frequency relationships have been constructed (Madsen et al., 2002, 2009). Observed sea-level data (1992-2007, i.e. 16 years) from the Drogden Fyr station in Øresund close to the Kalveboderne bay (Kystdirektoratet and Transportministeriet, 2007) were used to establish the storm surge statistics for the current climate.

\section{Extraction of extremes and modelling of their monthly distributions}

All extreme events were extracted from the basic data series on the basis that there should be $24 \mathrm{~h}$ between two extreme events, and the inter-event level should be lower than $30 \%$ of the highest value. A total of 271 extreme 3 -h duration rainfall events were extracted from the 30 years of rain data, and 204 extreme sea levels were extracted from the 16 years of data. The observations from the period where both gauges were recording is shown in Figure 3; 162 extreme rainfall events and 204 sea surge were registered, of which 49 events were concurrent (Figure 3, blue dots) when using thresholds of $6 \mathrm{~mm} / 3 \mathrm{~h}$ for rainfall and $0.3 \mathrm{~m}$ for sea level. These thresholds were used here to ensure a reasonable amount of concurrent observations while at the same time ensuring that only the observed extremes were included in the PDS modelling. 
Table 1 Parameters of the exponential distribution for precipitation for control and future scenario for each month

\begin{tabular}{|c|c|c|c|c|c|c|c|c|c|c|c|c|c|c|}
\hline & & & Jan & Feb & Mar & Apr & May & Jun & Jul & Aug & Sep & Oct & Nov & Dec \\
\hline \multirow[t]{3}{*}{ Control } & $\beta$ & $(\mathrm{mm} / 3 \mathrm{~h})$ & 6 & 6 & 6 & 6 & 6 & 6 & 6 & 6 & 6 & 6 & 6 & 6 \\
\hline & $\alpha$ & (mm/3 h/year) & 1.52 & 0.63 & 2.16 & 2.76 & 2.99 & 5.99 & 5.40 & 6.06 & 4.45 & 3.61 & 2.61 & 1.55 \\
\hline & $\lambda$ & $\left(\right.$ month $\left.^{-1}\right)$ & 0.016 & 0.011 & 0.011 & 0.023 & 0.041 & 0.071 & 0.061 & 0.085 & 0.059 & 0.047 & 0.029 & 0.017 \\
\hline \multirow[t]{3}{*}{ Future } & $\beta$ & (m) & 6 & 6 & 6 & 6 & 6 & 6 & 6 & 6 & 6 & 6 & 6 & 6 \\
\hline & $\alpha$ & (m/year) & 2.52 & 1.03 & 4.69 & 5.43 & 4.65 & 8.85 & 8.58 & 9.11 & 6.28 & 5.53 & 3.86 & 2.55 \\
\hline & $\lambda$ & $\left(\right.$ month $\left.^{-1}\right)$ & 0.036 & 0.016 & 0.015 & 0.017 & 0.035 & 0.072 & 0.060 & 0.057 & 0.055 & 0.080 & 0.029 & 0.016 \\
\hline
\end{tabular}

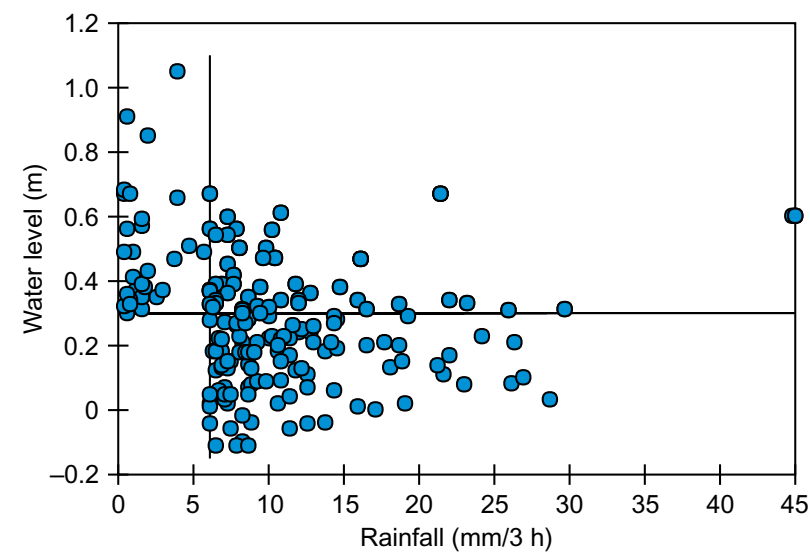

Figure 3 Concurrent dataset (1992-2007) for water level and rainfall. The extreme value region is defined by $6 \mathrm{~mm} / 3-\mathrm{h}$ rainfall and 0.3-m water level.

The extracted extreme value series were divided into monthly series, and the PDS parameters were estimated for each month assuming ED of the exceedances Eqn (7), as the number of observations in each month were too few to allow a more complex model such as the GPD Eqn (6). The results are shown in the upper parts of Table 1 and Table 3 for extreme rainfall and sea surges, respectively.

Annual exceedance series of extreme rainfall and sea level is modelled as a GPD Eqn (7) and ED Eqn (6), respectively.

\section{Prediction of future extremes}

Extreme rainfall intensities giving rise to pluvial flooding are not well represented in state-of-the art RCM simulations at the $25-50 \mathrm{~km}$ spatial grid scale, and linking of RCMs with ocean and estuary models to simulate storm surge is still in its infancy (Solomon et al., 2007). Therefore, crude assumptions must be made, and the inherent uncertainty of the projection is large because of incomplete knowledge about the processes governing the changes over time. The RCM model outputs available for the study on which the rainfall projection is based is from a high-resolution simulation using the RCM model HIRHAM4 (Christensen and Christensen, 2007). The simulation is run using a high-middle emission scenario describing a heterogeneous world with little economical integration, a continuously increasing

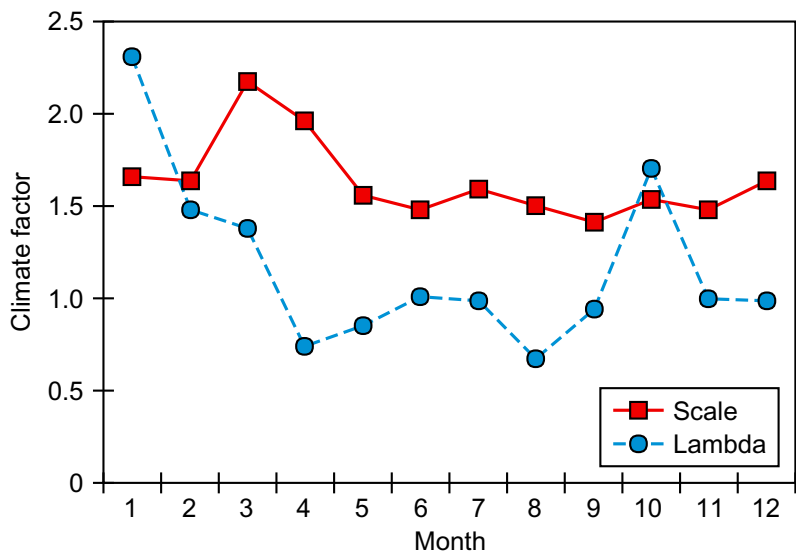

Figure 4 Climate factor (2071-2100 versus 1961-1990) for the parameters of an exponential distribution during each month of the year, based on regional climate model output cells corresponding to Denmark (Gregersen and Larsen, 2007).

population and a slow technological development, often denoted the A2 scenario (Nakicenovic et al., 2000). To keep consistency, the sea-level rise expected will be based on the same scenario. Furthermore, we chose to focus on changes over a period of 110 years, using 1961-1990 as control period and 2071-2100 as scenario period, in accordance with most of the IPCC literature (e.g. Christensen and Christensen, 2007).

\section{Extreme rainfall}

Climate factors for monthly PDS parameters for rainfall were obtained from a recent Danish RCM study using a $12 \mathrm{~km}$ spatial resolution (Gregersen and Larsen, 2007; Larsen et al., 2009). Figure 4 shows monthly climate factors for the Poisson intensity $(\lambda)$ and the scale parameter $(\alpha)$ of the monthly PDS models for 1-h rainfall intensities as obtained from Gregersen and Larsen (2007). According to Gregersen and Larsen (2007), the uncertainty of estimating the shape parameter $(\kappa)$ from the RCM output was too large to identify a change from the control to the future scenario period, and $\kappa$ was therefore assumed not to be influenced by climate change. We assume that these factors are also valid for 3-h rainfall and obtained monthly PDS parameters for 
Table 2 Changes in wind speed according to Rockel and Woth (2007). The parameters $\alpha$ and $\lambda$ are changed in the future scenario accordingly

\begin{tabular}{lcccc}
\hline & $\begin{array}{l}\text { 99th percentile mean } \\
\text { wind speed (m/s) } \\
\text { (Rockel and Woth, 2007) }\end{array}$ & $\begin{array}{l}\text { Changes in a future } \\
\text { A2 scenario (m/s) } \\
\text { (Rockel and Woth, 2007) }\end{array}$ & $\begin{array}{l}\text { 99th percentile mean } \\
\text { wind speed in a future } \\
\text { A2 scenario (m/s) }\end{array}$ & $\begin{array}{l}\text { Correspond } \\
\text { to which } \\
\text { month today? }\end{array}$ \\
\hline January & 14.8 & -0.17 & 14.7 & January \\
February & 13.8 & +0.6 & 14.4 & January \\
March & 13.6 & -0.5 & 13.1 & April \\
April & 12.9 & -0.7 & 12.2 & May \\
May & 12 & -0.4 & 11.6 & May \\
June & 11.2 & 0 & 11.2 & June \\
July & 11 & +0.3 & 11.3 & August \\
August & 11.3 & +0.3 & 11.6 & August \\
September & 12.4 & -0.4 & 12.5 & Sep \\
October & 13.2 & +0.3 & 13.1 & Nov \\
November & 13.3 & -0.2 & 14.2 & Oct \\
December & 14 & +0.2 & Dec \\
\hline
\end{tabular}

Table 3 Parameters of the exponential distribution for sea surges for control and future scenario for each month

\begin{tabular}{|c|c|c|c|c|c|c|c|c|c|c|c|c|c|c|}
\hline & & & January & February & March & April & May & June & July & August & September & October & November & December \\
\hline \multirow[t]{3}{*}{ Control } & $\beta$ & (m) & 0.30 & 0.30 & 0.30 & 0.30 & 0.30 & 0.30 & 0.30 & 0.30 & 0.30 & 0.30 & 0.30 & 0.30 \\
\hline & $\alpha$ & (m/year) & 0.25 & 0.20 & 0.18 & 0.17 & 0.07 & 0.04 & 0.05 & 0.08 & 0.11 & 0.15 & 0.19 & 0.17 \\
\hline & $\lambda$ & $\left(\right.$ month $\left.^{-1}\right)$ & 0.15 & 0.18 & 0.12 & 0.06 & 0.02 & 0.04 & 0.10 & 0.09 & 0.15 & 0.11 & 0.19 & 0.17 \\
\hline \multirow[t]{3}{*}{ Future } & $\beta$ & (m) & 0.80 & 0.80 & 0.80 & 0.80 & 0.80 & 0.80 & 0.80 & 0.80 & 0.80 & 0.80 & 0.80 & 0.80 \\
\hline & $\alpha$ & (m/year) & 0.25 & 0.25 & 0.17 & 0.07 & 0.07 & 0.04 & 0.08 & 0.08 & 0.11 & 0.19 & 0.15 & 0.17 \\
\hline & $\lambda$ & $\left(\right.$ month $\left.^{-1}\right)$ & 0.15 & 0.15 & 0.06 & 0.02 & 0.02 & 0.04 & 0.09 & 0.09 & 0.15 & 0.19 & 0.11 & 0.17 \\
\hline
\end{tabular}

the future scenario period by direct multiplication of the climate factors with the monthly PDS parameters estimated from the observations. The 'climate-adjusted' PDS parameters for 3-h rainfall are shown in the lower part of Table 1.

\section{Storm surge}

The level of storm surges is influenced by a change in global mean, in regional mean, land-uplift, and changes in the extremes. Changes in the extremes are assumed to be affected primarily by changes in the wind extremes, while the other processes are assumed to be constant in the future scenario and independent of changes in the extremes.

According to Meehl et al. (2007), the global sea water-level rise is projected to be $0.37 \mathrm{~m}(0.23-0.51 \mathrm{~m})$ for the A2 scenario, and due to regional differences, the water level is projected to increase additional $0.2 \mathrm{~m}$ around Denmark. A land-uplift will occur at a rate at $10 \mathrm{~cm} / 100$ years, which will reduce the impact of sea-level rise (Copenhagen Municipality, 2009). Based on this information, the local increase in sea level is assumed to be on average $0.5 \mathrm{~m}$ in the future scenario. The sea-level rise occurring throughout 2070-2100 is neglected. Therefore, the location parameter, $\beta$, in the PDS model is increased from 0.3 to 0.8 in the future scenario.

Rockel and Woth (2007) found that extreme wind events occur from October to March for a simulated control period
1960-1991, which is also the period where extreme storm surges happen. Based on their study, we have found that there is close agreement between characteristics of simulated wind extremes and observed surges. We use this correlation to predict characteristics of the future monthly surges in a 'space-for-time' approach, based on Euclidean distance between simulated present and future wind extremes. As an example, the future wind speed extremes in February is expected to be similar to the historical January, and therefore the scale $(\alpha)$ and Poisson $(\lambda)$ parameter for the future February is the same as for the historical January, recalling that the threshold value is adjusted according to the general patterns of average sea-level rise. The resulting changes in the wind extremes and their influence on occurrences of surges are summarised in Table 2, and the PDS parameters of the model is summarised in Table 3 (lower part).

\section{Generation of synthetic hazard time series}

For both rainfall and sea levels, and for both the control and the future scenario periods, synthetic daily time series were generated as explained in the Methodology section using MC simulation for 1000 years. The parameters used in the MC simulations are shown in Tables 1 and 3. These generated synthetic time series were then used as a basis for estimating non-seasonal PDS models for each hazard and each 

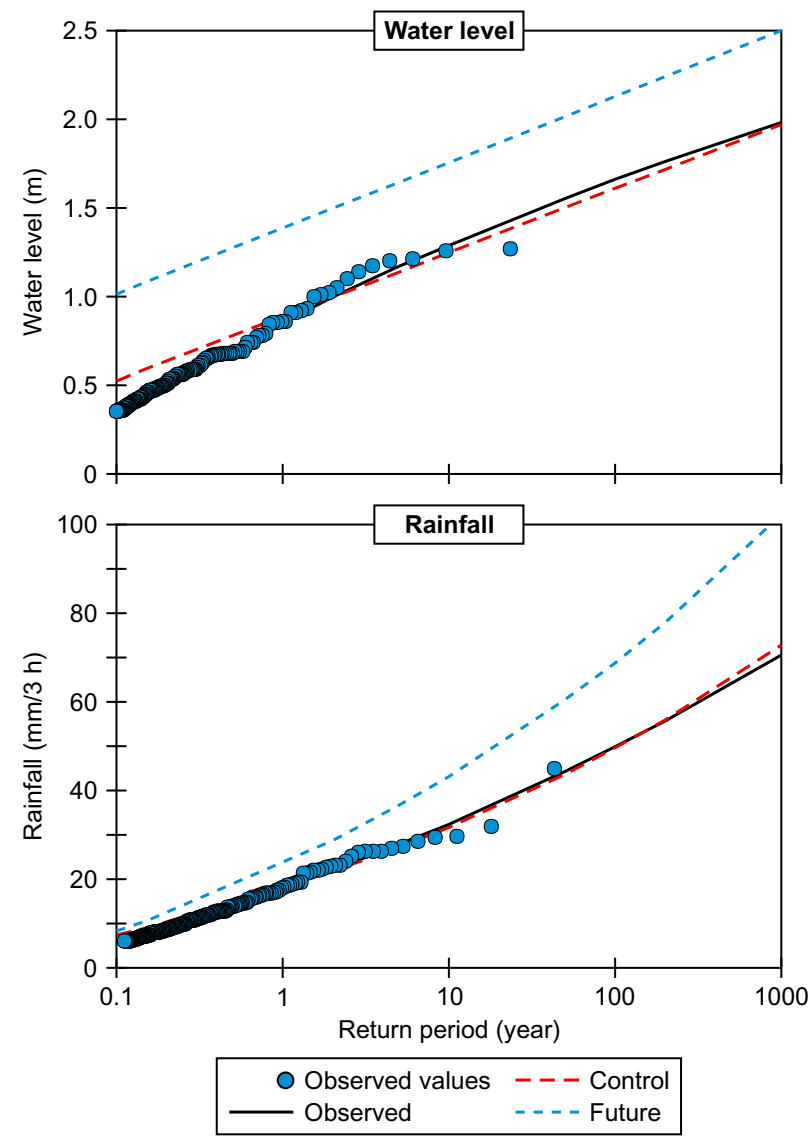

Figure 5 Partial duration series models for sea surge (top) and rainfall (bottom) for the observed series and the two simulated series, representing current (control) and anticipated future (future) climate. Observations are identical to the data shown in Figure 3 and are included to show the goodness of fit of the marginal models.

Table 4 Estimates of $\tau$ and $\theta$ based on the three series of extremes

\begin{tabular}{llll}
\hline & Observed & Control & Future \\
\hline$\tau$ & 0.082 & 0.088 & 0.076 \\
$\theta$ & 1.0893 & 1.0963 & 1.0827 \\
\hline
\end{tabular}

period. PDS models were also constructed based on the observed time series. The results are shown in Figure 5. Based on the figures, it seems reasonable to conclude that the marginal distributions for the control period resemble the observed data well.

\section{Copulas}

Kendall's Tau, $\tau$, and the corresponding Gumbel-Hougaard copula parameter, $\theta$, were calculated for each of the series (see Table 4). The correlation is positive, but very low for all series, indicating that the hazards are close to being independent of each other. Formal testing of goodness of fit of the copula function was not carried out because the under- lying assumption was that the correlation was only due to annual variation. The correlation for the control series is as high as for the observed series, justifying the assumptions about correlation structure between the two hazards. Interestingly, it seems that the correlation between the extremes is not higher in the future simulations, even though there is a larger overlap in time of concurrent events.

The overall return periods will, however, change substantially due to changes in the marginal distributions of both precipitation and surges. The concurrent return period of the bivariate copula for the control and future scenarios can be seen in Figure 6.

When comparing the future with the control scenario, the probabilities change, and the return periods for the future scenario period become smaller than for the control period. This indicates that a concurrent event will happen more often in the future. The difference in calculated return period for the joint exceedance probability ranges from less than one order of magnitude to almost three orders of magnitude as shown in Figure 7.

\section{Calculation of flood risk}

By simulating selected combinations of storm surge and rainfall in the study area by Mike Urban (DHI, 2011), it is possible to find the flooded area for different combinations of storm surge and rainfall. An example of the flooding extent in the area can be seen in Figure 2 (right). By interpolating the different combinations, a grid of the flooding extent can be made, resulting in the coloured background layer in Figure 6.

The risk analysis of the case study area can then be visualised as shown in Figure 6, representing $g_{2}(\cdot)$ by the amount of flooded area. The maximum cost for each return period is indicated with a red dot, and the blue markings of the return period curves indicate that the cost is less than $5 \%$ below the maximum cost. In that way, it can be seen for which combination of the two hazards the most damaging effect of a certain return period is. The results indicate that in the control period, the dominating hazard is rainfall, while in the future scenario, the dominating hazard for high-return periods is sea surges. For relatively low-return periods, the dominating hazard is still rainfall.

Figure 8 shows the change in maximum risk between the control and the future scenario as a function of return period as indicated in Figure 1. Integration of this curve over the return period will yield the overall maximum risk according to Eqn (1). In the case study, this integration would not yield realistic results because of the simple cost indicator. Indeed, Figure 8 highlights the shortcoming of using the amount of flooded areas as an indicator. The actual cost of flooding of the first 600-700 ha of land is low because the land is not developed for urban use. However, the 

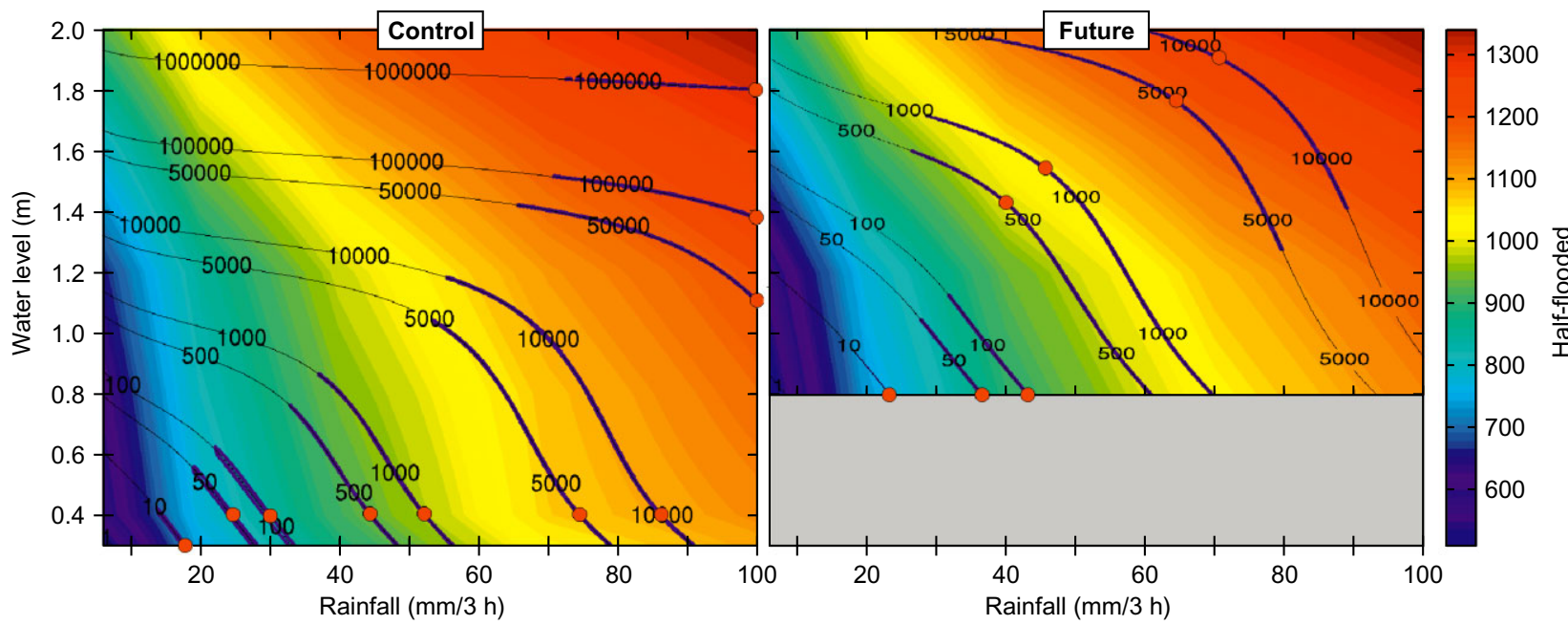

Figure 6 Result of the risk calculations for control (left) and future (right) scenarios. The grey shaded area in the right figure shows the area where the marginal model for sea level is no longer valid due to sea-level rise. The coloured background show the amount of flooded area in hectares $\left(10000 \mathrm{~m}^{2}\right)$ while the lines show the return periods of the hazards. The red dot on the return period curves show where the vulnerability indicator is highest, and the blue markings show where the vulnerability indicator is less than $5 \%$ below the maximum value.

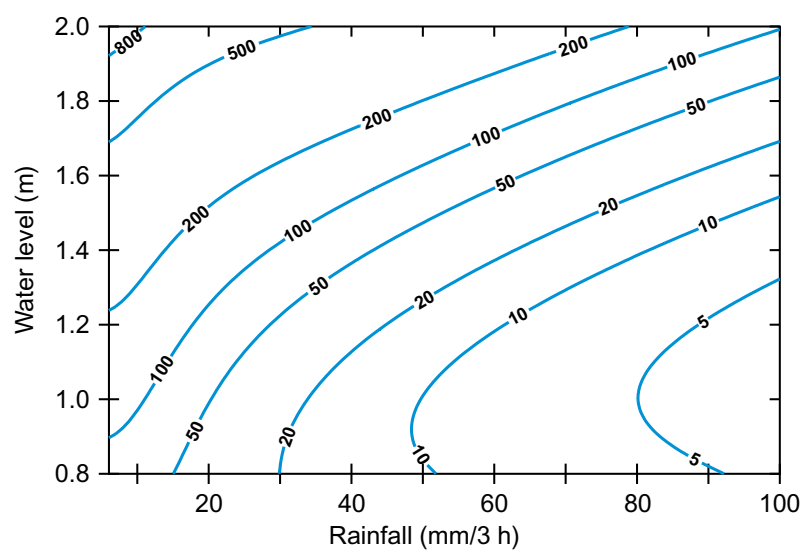

Figure 7 The ratio between return period for the control and future periods. In general, the return period is decreased from less than one to almost three orders of magnitude from control to future.

remaining areas are fully developed urban areas with a high cost of flooding per unit area. Therefore, the actual change in risk is much higher than the change in calculated risk would indicate.

\section{Discussion and conclusion}

The main focus of the paper is to outline a methodology suitable for studying floods caused by several concurrent hazards and to study the influence of anticipated climateinduced changes for these hazards. The case study indicates that changes in the return periods of one to almost three

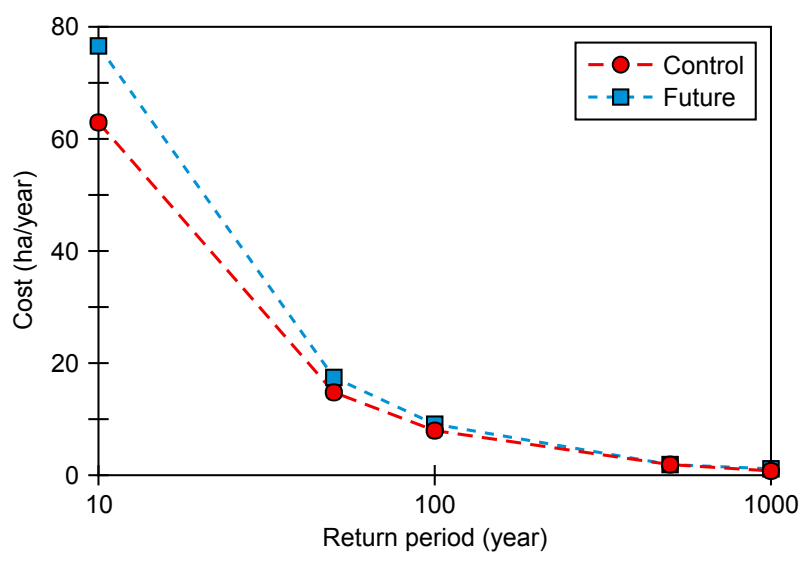

Figure 8 Maximum risk of the control and future scenarios as a function of return period.

orders of magnitude is likely and that sea surge will become more detrimental than precipitation for some return periods for the Greater Copenhagen region. The results of the analysis should be interpreted with caution. Indeed, we acknowledge that there are some weaknesses in the application of the framework that contribute to the uncertainty of the analysis. These shortcomings are discussed below.

First, the assumption of lack of correlation between the two hazards may seem unrealistic from a meteorological point of view. Both precipitation extremes and sea surges occur when large fronts are passing over the catchment. However, as the results indicate, the assumption seems good in the sense that historical observations can be reconstructed using a MC framework. We interpret this result as in indi- 
cation that even though some underlying meteorological processes suggest a correlation, the processes of generating extremes are quite different from the average of these processes.

As discussed in section 2.3, the ideal prediction of future extremes would be based on several downscaling experiments with a range of emission scenarios and driving global models with different sensitivity to greenhouse gas emissions. However, these are not generally available for relevant urban flood risk hazards, and in any case, the uncertainty would be underestimated because of incomplete knowledge. As an example of such incomplete knowledge, the recent suggestions of higher average sea-level rise can be mentioned, as well as rather large changes in precipitation extremes in the catchment over the last two decades. As an example of such changes, we note that two precipitation events larger than the maximum precipitation hazard modelled in this study have been recorded in the greater Copenhagen region during 2010 and 2011.

Even given the shortcomings discussed above, it seems reasonable to conclude that the risk of concurrent hazards is low for the catchment in question. It is also reasonable to assume that the suggested change in the relative importance of the hazards is a tangible outcome that is quite certain in spite of the uncertainties.

The initial hypothesis of a higher correlation between the two hazards due to a higher overlap in time was not confirmed by the results of the study. This can to some extend be a result of inadequate predictions of the future behaviour of extremes. A research programme has just been initiated to study the processes of sea surges for the Baltic region.

\section{References}

Arnbjerg-Nielsen K. \& Fleischer H.S. Feasible adaptation strategies for increased risk of flooding in cities due to climate change. Water Sci Technol 2009, 60, (2), 273-281.

Chen A.S., Djordjevic S., Leandro J. \& Savic D.A. An analysis of the combined consequences of pluvial and fluvial flooding. Water Sci Technol 2010, 62, (7), 1491-1498.

Chowdhary H., Escobar L.A. \& Singh V.P. Copulas for multivariate flood frequency analysis. In: S.K. Jain, V.P. Singh, V. Kumar, R. Kumar, R.D. Singh \& K.D. Sharma, eds. Proceedings of the International Conference on Water, Environment, Energy and Society (WEES-2009). New Delhi, India: Allied Publishers Pvt. Ltd., 2009, 596-607.

Christensen J.H. \& Christensen O.B. A summary of the PRUDENCE model projections of changes in European climate by the end of this century. Clim Change 2007, 81, (Suppl.), $7-30$.

Copenhagen Municipality. Copenhagen Climate Action Plan. (In Danish: Københavns klimaplan.). 2009 [online] http:// 131.165.91.1/sitecore/content/Subsites/CityOfCopenhagen/
SubsiteFrontpage/LivingInCopenhagen/ /media/ 491B1EC4F6B14FC9A31F9373AA54F02D.ashx Accessed 17 November 2011.

DHI. DHI software. DHI, Hoersholm, Denmark 2011 [online]. http://www.dhigroup.com/ Accessed 17 November 2011.

DMI. The Danish Water Committee Rain Gauge System. (In Danish: Spildevandskomitéens regnmålersystem.) 2009 [online] http://www.dmi.dk/dmi/index/erhverv/ spildevandskomiteens_regnmaalersystem.htm. Accessed 17 November 2011.

EU. Directive 2007/60/EC of the European Parliament and of the council of 23 October 2007 on the assessment and management of flood risks. Official journal of the European Union, 6.11.2007, L288/27 - 34, 2007.

Genest C., Remillard B. \& Beaudoin D. Goodness-of-fit tests for copulas: a review and a power study. Insur Math Econ 2007, 44, (2), 199-213.

Gregersen I.B. \& Larsen A.N. Development in extreme precipitation over Europe due to climate change. MSc Thesis. Department of Environmental Engineering, Technical University of Denmark, 2007.

Grum M., Jørgensen A.T., Johansen R.M. \& Linde J.J. The effect of climate change on urban drainage: an evaluation based on regional climates model simulations. Water Sci Technol 2006, 54, (6-7), 9-15.

Jeppesen E., Kronvang B., Meerhoff M., Søndergaard M., Hansen K.M., Andersen H.E., Lauridsen T.L., Liboriussen L., Beklioglu M., Özen A. \& Olesen J.E. Climate change effects on runoff; catchment phosphorous load and lake ecological state, and potential adaptations. J Environ Qual 2009, 38, 1930-1941.

Jørgensen H.K., Rosenørn S., Madsen H. \& Mikkelsen P.S. Quality control of rain data used for urban runoff systems. Water Sci Technol 1998, 37, (11), 113-120.

Kystdirektoratet and Transportministeriet. Extreme sea level statistics for Denmark. Copenhagen: Danish Coastal Authority, 2007.

Larsen A.N., Gregersen I.B., Christensen O.B., Linde J.J. \& Mikkelsen P.S. Potential future increase in extreme one-hour precipitation events over Europe due to climate change. Water Sci Technol 2009, 60, (9), 2205-2216.

Madsen H. EVA - extreme value analysis - technical reference and documentation. Hoersholm: DHI, 2005.

Madsen H., Arnbjerg-Nielsen K. \& Mikkelsen P.S. Update of regional intensity-duration-frequency curves in Denmark: tendency towards increased storm intensities. Atmos Res 2009, 92, (3), 343-349.

Madsen H., Mikkelsen P.S., Rosbjerg D. \& Harremoës P. Regional estimation of rainfall intensity-duration-frequency curves using generalized least squares regression of partial duration series statistics. Water Resour Res 2002, 38, (11), 21-1-21-11.

Meehl G.A., Stocker T.F., Collins W.D., Friedlingstein P., Gaye A.T., Gregory J.M., Kitoh A., Knutti R., Murphy J.M., 
Noda A., Raper S.C.B., Watterson I.G., Weaver A.J. \& Zhao Z.-C. Global climate projections. In: S. Solomon, D. Qin, M. Manning, Z. Chen, M. Marquis, K.B. Averyt, M. Tignor \& H.L. Miller, eds. Climate change 2007: the physical science basis. Contribution of working group I to the fourth assessment report of the intergovernmental panel on climate change. Cambridge, United Kingdom and New York, NY, USA: Cambridge University Press, 2007, 746-846.

Mikkelsen P.S., Madsen H., Rosbjerg D. \& Harremöes P. Properties of extreme point rainfall III: identification of spatial inter-site correlation structure. Atmos Res 1996, 40, 77-98.

Morita M. Flood risk analysis for determining optimal food protection levels in urban river management. J Flood Risk Manag 2008, 1, 142-149.

Myronidis M., Emmanouloudis D., Stathis D. \& Stefanidis P. Integrated flood hazard mapping in the framework of the EU directive on the assessment and management of flood risks. Fresenius Environ Bull 2009, 18, (1), 102 -111.

Nakicenovic N., Alcamo J., Davis G., de Vries B., Fenhann J., Gaffin S., Gregory K., Grübler A., Jung T.Y., Kram T., La Rovere E.L., Michaelis L., Mori S., Morita T., Pepper W., Pitcher H., Price L., Raihi K., Roehrl A., Rogner H.-H., Sankovski A., Schlesinger M., Shukla P., Smith S., Swart R., van Rooijen S., Victor N. \& Dadi Z. IPCC special report on emissions scenarios. Cambridge, United Kingdom and New York, NY, USA: Cambridge University Press, 2000, 599.

Nelsen R.B. An introduction to copulas, 2nd edn. New York: Springer Series in Statistics, 2006.

Onof C. \& Arnbjerg-Nielsen K. Quantification of anticipated future changes in high resolution design rainfall for urban areas. Atmos Res 2009, 92, (3), 350-363.

Pinya M.A.S., Madsen H. \& Rosbjerg D. Assessment of the risk of inland flooding in a tidal sluice regulated catchment using multi-variate statistical techniques. Phys Chem Earth 2009, 34, (10-12), 662-669.

Rockel B. \& Woth K. Extremes of near-surface wind speed over Europe and their future changes as estimated from an ensemble of RCM simulations. Clim Change 2007, 81, 267-280.

van Roosmalen L., Sonnenborg T.O. \& Jensen K.H. Impact of climate and land use change on the hydrology of a large-scale agricultural catchment. Water Resour Res 2009, 45, (W00A15), 1-18.

Rosbjerg D. Estimation in partial duration series with independent and dependent peak values. J Hydrol 1985, 76, (1-2), $183-195$.
Schmitt T.G., Thomas M. \& Ettrich N. Analysis and modelling of flooding in urban drainage systems. J Hydrol 2004, 299, 300-311.

Schölzel C. \& Friederichs P. Multivariate non-normally distributed random variables in climate research - introduction to the copula approach. Nonlinear Processes Geophys 2008, 15, 761-772.

Serinaldi F. \& Grimaldi S. Fully nested 3-copula: procedure and application on hydrological data. J Hydrol Eng 2007, 12, (4), 420-430.

Singh V.P. \& Zhang L. IDF curves using the Frank Archimedean copula. J Hydrol Eng 2007, 12, (6), 651-662.

Sklar A. Fonctions de repartition àn dimensions et leurs marges. 8 , Paris: Publishing Institute of Statistical University of Paris, 1959, 229-231.

Smith M.B. Comment on 'analysis and modelling of flooding in urban drainage systems'. J Hydrol 2006, 317, 355-363.

Solomon S., Qin D., Manning M., Chen Z., Marquis M., Averyt K.B., Tignor M. \& Miller H.L., eds. Climate Change 2007. The Physical Science Basis. Contribution of Working Group 1 to the Fourth Assessment Report of the Intergovernmental Panel on Climate Change. 2007 [online] http:// ipcc.ch/publications_and_data/ar4/wg1/en/contents.html Accessed 17 November 2011.

Sonnenborg T.O., Christensen B.S.B., van Roosmalen L. \& Henriksen H.J. Klimaændringers betydning for vandkredsløbet i Danmark. Vol. 22 Danmarks og Grønlands Geologiske Undersøgelse, 2006.

STAHY. References on Copula Function topic. 2011 [online] http://www.stahy.org/Activities/STAHYReferences/ ReferencesonCopulaFunctiontopic/tabid/78/Default.aspx Accessed 17. November 2011.

Sto. Domingo N.D., Refsgaard A., Mark O. \& Paludan B. Flood analysis in mixed-urban areas reflecting interactions with the complete water cycle through coupled hydrologic-hydraulic modelling. Water Sci Technol 2010, 62, (6), 1386-1392.

Viessman W. \& Lewis G.L. Introduction to hydrology, 5th edn. Upper Saddle River, NJ: Prentice Hall, 2003.

Yue S. Applying bivariate normal distribution to flood frequency analysis. Water Int 1999, 24, (3), 248-254.

Zhang L. \& Singh V.P. Bivariate rainfall frequency distributions using Archimedean copulas. J Hydrol 2007, 332, 93-109.

Zhou Q., Mikkelsen P.S., Halsnæs K. \& Arnbjerg-Nielsen K. Framework for economic pluvial flood risk assessment considering climate change effects and adaptation benefits. J Hydrol 2012, 414-415, 539-549. 